Title - Speak No Evil: Understanding Hermeneutical (In)justice

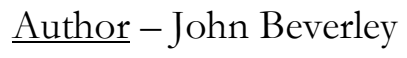

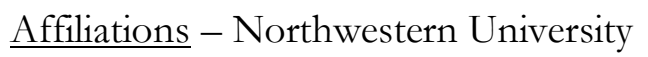

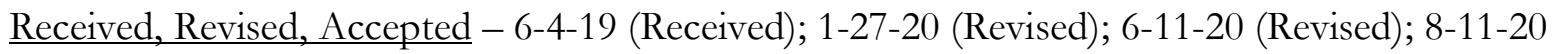

(Accepted)

Abstract - Miranda Fricker's original presentation of Hermeneutical Injustice left open theoretical choice points leading to criticisms and subsequent clarifications with the resulting dialectic appearing largely verbal. The absence of perspicuous exposition of hallmarks of Hermeneutical Injustice might suggest scenarios exhibiting some - but not all - such hallmarks are within its purview when they are not. The lack of clear hallmarks of Hermeneutical Injustice, moreover, obscures both the extent to which Fricker's proposed remedy Hermeneutical Justice - roughly, virtuous communicative practices adequately addresses the injustice, and the accuracy of criticisms suggesting that Hermeneutical Justice is insufficient to the task. In what follows, after briefly defending necessary and sufficient conditions for what I take to be the best candidate interpretation of Hermeneutical Injustice, I build on recent work on moral responsibility to construct and defend a rigorous explication of Hermeneutical Justice.

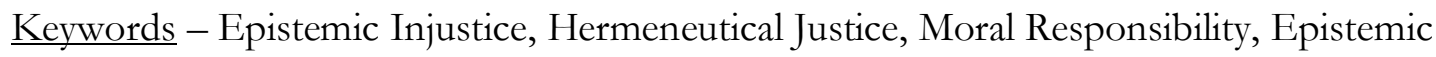

Responsibility

Corresponding Author Email - johnbeverly2021@u.northwestern.edu

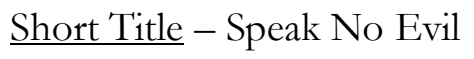




\section{Speak No Evil: Understanding Hermeneutical (In)justice ${ }^{1}$}

\section{Introduction}

Gaps in collective hermeneutical resources stemming from prejudice may result in members of marginalized groups being unable to render harmful experiences intelligible to themselves or others (Fricker, 2007, pg. 1; Fricker, 2016, pg. 166). Miranda Fricker identifies such situations as instances of Hermeneutical Injustice HI. For example, prior to the introduction of the term "sexual harassment," there was a gap ${ }^{2}$ in the relevant collective understanding - the intersection of hermeneutical resources among groups that just about anyone can be expected to draw upon and be understood by anyone else (Fricker, 2016, pg. 161). This lacuna hindered attempts by, say, women harassed in the workplace, from fully understanding these harmful experiences.

Fricker's original presentation of $\mathbf{H I}$ left open theoretical choice points leading to criticisms (Dotson, 2012; Mason, 2013; Medina, 2013) and subsequent clarifications (Fricker, 2016) with the resulting dialectic appearing largely verbal. The absence of perspicuous exposition of hallmarks of HI might suggest scenarios exhibiting some - but not all - such hallmarks are within its purview when they are not. The lack of clear hallmarks of $\mathbf{H I}$, moreover, obscures both the extent to which Fricker's proposed remedy Hermeneutical Justice $\mathbf{H J}$ - roughly, virtuous communicative practices -

\footnotetext{
${ }^{1}$ Acknowledgements: Many thanks to Hansen Breitling, Eskil Elling, Christiana Eltise, Alicia Kennedy, Hollen Reischer, and Kasey-Hettig-Rolfe and for various discussions on the content of this paper. Hollen, in particular, deserves more thanks than I can express here, due to patience, insights, and influence it is hard to identify in brief. Thanks to Beth Barker, Susan Bencomo, Nathaly Garcia, Sandy Goldberg, Regina Hurley, Nate Lauffer, Mauricio Mulaff Masi, Gisela Reyes, Jon Vandenburgh, and Stephen White for critical feedback over two talks which vastly improved the content. I am, moreover, eternally grateful to Megan Hyska, Jose Medina, William Paris, and an anonymous reviewer at Episteme for insightful, supportive, critical feedback on previous drafts. I am fortunate to be part of such a strong philosophical community.

${ }^{2}$ Not all "gaps" result in HI. First, it is plausible collective hermeneutical resources contain a confounding surplus resulting in, say, suspension of belief. But since this "gap" operates at the level of belief it will not result in HI (Fricker, 2016). Second, agents who have not inferred implicit resources from explicit hermeneutical resources exhibit a "gap" but this also operates at the level of belief. Corollary: generating new hermeneutical resources must sometimes arise ex nibilo. Suppose otherwise. Presumably, a conceptual definition corresponding to the phrase "sexual harassment" could have been constructed by Woods prior to introducing the term based on available conceptual resources, e.g. this or that behavior with this or that intention. But that suggests "sexual harassment" was implicit in the existing resources and Woods simply failed to identify it. Hence, this is a failure at the level of belief and so not HI. But this is HI. Hence, the concept was not implicit in existing resources.
} 
adequately addresses the injustice, and the accuracy of criticisms suggesting that $\mathbf{H J}$ is insufficient to the task. In what follows, after briefly defending necessary and sufficient conditions for what I take to be the best candidate interpretation of $\mathbf{H I}$, I defend a rigorous explication of $\mathbf{H J}$.

More specifically, in Section 2 I argue in favor of necessary and sufficient conditions for $\mathbf{H I}$ and show how they might clarify verbal disputes. In Section 3, I explicate $\mathbf{H J}$ as cultivation of virtuous conversational skills directed towards charitable understanding of marginalized speakers. I articulate epistemic and moral aspects of $\mathbf{H J}$ as independently motivated context-sensitive standing responsibilities we all share and - building on previous work (Beverley, 2016; Beverley \& Beebe, 2017) - observe one consequence of understanding $\mathbf{H J}$ in this manner is that certain agents may bear substantial responsibilities in contexts exhibiting HI. In Section 4, noting Fricker might balk at such a consequence since $\mathbf{H I}$ is a structural injustice often lacking perpetrators, I show there is conceptual space in Fricker's account for responsibility I claim should constitute $\mathbf{H J}$, suggest the proposed context-sensitive principles may provide responses to critics who question the efficacy of Fricker's characterization of $\mathbf{H J}$, and illustrate how these principles provide clear mechanisms for analyzing responsibility among clinical psychologists and in cases where marginalized individuals might be expected to educate privileged individuals. Given the explanatory benefits, plausibility of applications, etc., I conclude Fricker has overwhelming reasons to adopt the explication of $\mathbf{H J}$ offered here.

\section{Explicating Hermeneutical Injustice}

Fricker's initial characterization of $\mathbf{H I}$ as gaps in collective epistemic resources underwritten by prejudice, left room for interpretation. Following (Goetze, 2018)'s characterization, some (Dotson, 2012; Mason, 2013) understood "collective epistemic resource" as the only available epistemic resources across marginalized and non-marginalized communities. This reading entailed marginalized groups could not in principle develop local epistemic resources; either everyone had a 
given epistemic resource or no one did. Since marginalized groups clearly do develop local epistemic resources not necessarily shared by the collective, Fricker's characterization of $\mathbf{H I}$ thus seemed problematically exclusionary. Others (Medina, 2013) understood "collective epistemic resource" as the union of epistemic resources across marginalized and non-marginalized communities, but argued Fricker's account of HI overlooked ways in which members of marginalized communities develop local hermeneutical resources to understand harmful experiences. Marginalized individuals might avoid $\mathbf{H I}$ when reflecting on harmful experiences or communicating with other members of their local community, but experience $\mathbf{H I}$ when attempting to communicate with non-marginalized individuals who lack those local hermeneutical resources. Fricker's initial characterization of $\mathbf{H I}$ seemed to overlook this distinction.

\subsection{Verbal Disputes, Conceptual Gaps, and Extension}

Fricker (Fricker, 2016) clarified "collective" was to be understood as the intersection of epistemic resources any member of the relevant community could be expected to have access to. This allows that marginalized communities may have local epistemic resources not shared by the larger community, and so avoids concerns of the first sort. To address concerns of the second sort, Fricker extended $^{3}$ the initial characterization of $\mathbf{H I}$ to a spectrum of species of the phenomena. On one boundary are paradigmatic cases of $\mathbf{H I}$ - Carmita Wood experiencing sexual harassment before coining the term - called maximal $\mathbf{H I}$, since the gap in collective epistemic resources is global. On the other boundary are cases where the gap in collective resources is local, called minimal $\mathbf{H I}$, which involve marginalized individuals sufficiently equipped with hermeneutical resources to understand their harmful experiences, but who are unable to be understood by those lacking the same resources.

${ }^{3}$ Fricker claims "... a commitment to the existence of localized interpretive practices...is present....in the...original account of hermeneutical injustice.” (Fricker, 2016, pg. 167). I am skeptical. First, extending the original theory to maximal/minimal HI hardly shows they were implicit; theory extensions are cheap. One can consistently extend a minimal linear order to either a dense or discrete order, but not both. Similarly, Fricker's original account could be consistently extended in ways inconsistent with maximal/minimal HI. Second, appealing to Joe (Fricker, 2016, pg. 2016) as hermeneutically marginalized as evidence of minimal HI is questionable (Romdenh-Romluc, 2016). 
Fricker claims Joe from the novel Enduring Love exhibits minimal HI: Joe is being stalked by a religious zealot, but is unable to articulate his harmful experiences to police, as his stalker has not strictly speaking - committed a crime. ${ }^{4}$

The preceding disputes, it seems, stemmed largely from ambiguity in Fricker's initial presentation of $\mathbf{H I}$; Fricker's clarifications seem adequate to address the concerns. More clarification seems needed, however, as evidenced by recent discussion of whether scenarios involving certain types of abuse exhibit $\mathbf{H I}$. One concern is that $\mathbf{H I}$ involving individuals 'unable to render a harmful experience intelligible' is ambiguous. It might be understood as suggesting $\mathbf{H I}$ is present even if an individual does not attempt to render harmful experiences intelligible as long as they would have difficulty were they to try. It might alternatively be understood as suggesting $\mathbf{H I}$ is present only when there are attempts to render a harmful experience intelligible. Clearing this up is important since, as one example, Jose Medina has claimed marginalized individuals who are persistently and extensively excluded from participating in meaning-making and meaning-sharing, may experience a species of $\mathbf{H I}$ he calls hermeneutical death, the loss of the capacity to participate in these practices (Medina, 2017a; 2017b). But if HI as Fricker understands requires an individual actually struggle to make sense of such experiences, then it seems hermeneutical death does not count as HI. From another direction, even assuming the relevant gap is understood as the intersection of collective hermeneutical resources, it is unclear whether Fricker's characterization of $\mathbf{H I}$ requires a literal absence of resources, or allows that gaps might arise due to a surplus of resources, some being obscured by others. Katherine Jenkins, for example, recently applied (Jenkins, 2017, pg. 191-2) Fricker's account of $\mathbf{H I}$ to cases of domestic abuse and sexual violence, arguing that when persistent social misunderstandings of, say, domestic abuse conflict with relevant legal definitions - as often

\footnotetext{
${ }^{4}$ This is precisely the case Fricker used to introduce incidental HI (Fricker, 2007, pgs. 156-8); Fricker's suggestion that minimal HI was already included in the original account, suggests these are the same phenomenon.
} 
occurs during domestic abuse trials - victims may struggle to render experienced harms intelligible.

Jenkins concludes such cases exhibit $\mathbf{H I}$. However, if $\mathbf{H I}$ requires a literal absence of hermeneutical resources - rather than allowing the gap may exist due to a surplus of resources obscuring those needed to understand the harmful experience - then the phenomenon Jenkins identifies does not, in fact, count as $\mathbf{H I}{ }^{5}$ From yet another direction, Fricker claims the relevant gap in collective hermeneutical resources must stem from hermeneutical disadvantage to count as $\mathbf{H I}$, but this runs the risk of overlooking that individuals often have hermeneutical disadvantages and advantages, as well as the importance of how such asymmetries arise and are sustained. ${ }^{6}$

So, though our main goal in this article is explication of the remedy of $\mathbf{H I}$, it is worth clarifying hallmarks of the injustice, so we have the target phenomenon in full view. Given the remaining ambiguity in Fricker's presentations of $\mathbf{H I}$, it is not enough to simply quote Fricker. We must instead excavate some of these hallmarks ourselves. ${ }^{7}$

\subsection{Manifestation Condition and Hermeneutical Marginalization}

Consider a paradigmatic case of $\mathbf{H I}$ :

CASE 1: Sue was abused from childhood to adolescence and developed coping skills which disinclined Sue from reflecting on harmful experiences, e.g. habits of ignoring psychological/physical pain, tendency to dissociate, ${ }^{8}$ fusion with thoughts, etc. As an adult, Sue realizes her psychological development and dispositions differ significantly from acquaintances. Sue eventually acquires cognitive dispositions that incline her to reflect on and attempt to render intelligible past experiences of trauma and how they influence her present identity and interpersonal relationships. However, in Sue's community there are no collective resources adequate for understanding what we would characterize as child abuse and this absence owes to structural prejudice

${ }^{5}$ See (Mason, 2020) who observes this commitment of Fricker's, but argues HI should be understood more broadly. ${ }^{6}$ (Simion, 2018, pg. 315-6) claims - contra Fricker - what is essential to $\mathbf{H I}$ is that it is brought about unjustly, rather than via unjust marginalization as advantaged groups may be treated unjustly. Given the supplement to Fricker's account outlined below, namely, of weighing hermeneutical advantages to disadvantages in the analysis of hermeneutical marginalization, Fricker can make sense of Simion's example without needing to expand constraints on HI. See (Mason, 2020) for additional discussion.

${ }^{7}$ Many thanks to an anonymous reviewer at Episteme whose comments suggested I emphasize this point. ${ }^{8}$ (van Loon \& Kralik, 2005) and (Ward, 1988) illustrate childhood coping strategies manifesting in adulthood, e.g. repression, emotional insulation, dissociation. These "avoidant strategies" (Futa, Nash, Hansen, \& Garbin, 2003) help create a sense of control through avoiding emotions. 
concerning women and children. Consequently, Sue struggles and fails to render her harmful experiences intelligible to herself and others.

Reflection on CASE 1 reveals hallmarks of $\mathbf{H I}$. $^{9}$ In various places, Fricker maintains $\mathbf{H I}$ arises only when an agent struggles to make sense of an experience. ${ }^{10,11}$ The when and where of $\mathbf{H I}$ is tethered to those affected who try and fail to render their experiences intelligible. This implies if an agent is not attempting to render their harmful experience intelligible, there is no HI. Fricker thus accepts what I will call the Manifestation Condition (MC):
MC Case $\mathrm{C}^{12}$ involving agent $\mathrm{S}$ exhibits $\mathbf{H I}$ only if $\mathrm{S}$ attempts to render a relevant harmful experience intelligible in $\mathrm{C}$

MC might initially appear problematic. Suppose Sue is busy at work, momentarily distracted, or sleeping, and so not attempting to make sense of her harmful experiences. If $\mathbf{M C}$ is true, Sue is not subjected at those times to an injustice that undermines her abilities to render her experiences intelligible. That seems false.

But this is too quick. ${ }^{13}$ Fricker distinguishes $\mathbf{H I}$ from Hermenentical Marginalization HM: a state of affairs exhibiting non-accidental inequality between individuals or groups that provides the background condition against which instances of $\mathbf{H I}$ manifest. ${ }^{14}$ An analogy makes the point clear:

\footnotetext{
'It is worth noting Fricker's characterization of epistemic injustice has gained traction among psychology researchers keen on developing intervention strategies for individuals exhibiting symptoms similar to those described here (Sullivan, 2019; Kyratsous \& Sanati, 2016; Kverme, et. al., 2019)

10 “...hermeneutical injustice comes only when the background condition is realized in a more or less doomed attempt...to render an experience intelligible...” (Fricker, 2007, pg. 159); “The hermeneutical inequality that exists, dormant, in a situation of hermeneutical marginalization erupts in injustice only when some actual attempt at intelligibility is handicapped...” (Fricker, pg. 159). Italics added.

${ }^{11}$ (Goetze, 2018)'s revised definition of hermeneutical injustice reflects $\mathbf{M C}$ as well: “...primary harm of hermeneutical injustice is that the subject has some... social experience that at some crucial moment lacks intelligibility." As does (Hanel, 2017, pg. 2010) "As long as the subject of hermeneutical disadvantage undertakes no attempt to understand her experience...there is no hermeneutical injustice..."

${ }^{12}$ Embedded in "case" as used in what follows is a temporal index, e.g. "at time t".

${ }^{13}$ But not uncharitable: "A hermeneutical injustice is done when a collective hermeneutical gap impinges so as to... disadvantage some group(s)... which... is effectively discriminatory.” (Fricker, 2007, pg. 162) “...the conceptual lacuna which handicaps her as an interpreter of her experience entails a hermeneutical injustice. (Fricker, 2012) 14“...the conditions of hermeneutical injustice (namely, hermeneutical marginalization)..." (Fricker, 2006, pg. 174); "...hermeneutical marginalization...leaves practitioners susceptible to hermeneutical injustice whenever they should attempt to render the experience intelligible...” (Fricker, 2016, pg. 166); “...hermeneutical injustice and its precondition, hermeneutical marginalization.” (Jenkins \& Fricker, 2017, pg. 268) “...the primary harm of hermeneutical injustice consists in situated hermeneutical inequality..." (Fricker, 2007, pg. 162). See too (Goetze, 2018, pg. 81).
} 
Salt is disposed to initiate a dissolving process, if placed in background conditions, but salt being so disposed does not entail it ever will; dispositions and associated processes are only correlated (Williams, 2019; Smith, 2016; Lowe, 2006). Analogously, Fricker seems to hold: agents are to salt as $\mathbf{H M}$ is to water and as manifesting $\mathbf{H I}$ is to dissolving. This analogy makes sense of CASE 1, which exhibits $\mathbf{H M}$, dispositions to manifest $\mathbf{H I}$, and manifestation of $\mathbf{H I}$. Hence, this counts as an instance of HI. And it also makes sense of why nearby scenarios which exhibit $\mathbf{H M}$ but not $\mathbf{M C}$, do not count as instances of $\mathbf{H I}$. Individuals in such cases are more like iron than salt, in a cup of water. And neither HI nor dissolving necessarily manifests in such respective setups. If the preceding analogy correctly describes the relationship between $\mathbf{H I}$ and $\mathbf{H M}$, then it seems Fricker is committed to:

\section{HI-HM If case $C$ exhibits $\mathbf{H I}$, then $C$ exhibits $\mathbf{H M}$}

Which links manifestations to background conditions and makes all the difference when responding to the above objection. While Sue is not struggling to render her harmful experiences intelligible to herself or others, she nevertheless operates against this background condition which would undermine her attempts at doing so, and in that way is marginalized. ${ }^{15}$ Our objector may be unmoved, and insist Sue in CASE 1 exhibits $\mathbf{H I}$ even when, say, sleeping. ${ }^{16}$ But it is not clear what is gained in claiming $\mathbf{H I}$ in this case over mere $\mathbf{H M}$. Moreover, rejecting $\mathbf{M C}$ suggests there is little to distinguish $\mathbf{H I}$ and $\mathbf{H M}$ making it unclear what role this distinction plays in Fricker's theory. Altogether then: Reflection on CASE 1 suggests two hallmarks of $\mathbf{H I}$, namely, that relevant

\footnotetext{
${ }^{15}$ It is in this respect that marginalized individuals operate under "holes in the ozone layer." (Fricker, 2006, pg. 161). ${ }^{16}$ More charitably, one might reject MC for a weaker necessary condition on $\mathbf{H I}$, namely, that agents need only be disposed to render harmful experiences intelligible. Call this the Disposition Condition (DC). Understanding HI in this manner suggests Sue exhibits HI when busy, sleeping, etc., if she has the relevant cognitive dispositions. Besides there being textual support for Fricker accepting $\mathbf{M C}$ rather than the weaker DC, there seem theoretical benefits. With DC accepted, HI appears little different from HM, suggesting hermeneutical justice is proposed to address something nearby to HM. But seeking to address $\mathbf{H M}$ by simply cultivating virtues of listening seems - to put it bluntly ineffective at best and problematically insensitive at worst.
} 
individuals must at least attempt to render harmful experiences intelligible and this must operate against a background of hermeneutical marginalization. ${ }^{17}$

\subsection{Coercion, Hermeneutical Disadvantage, and Advantage}

Consider next:

CASE 2: Sally became pregnant at 15, dropped out of school, married at 16, had more children with her husband Mike, and was a "house wife" who relied on Mike for support. Mike was psychologically and physically abusive. Sally developed coping skills which disinclined Sally from reflecting on these harmful experiences, e.g. habits of ignoring psychological/physical pain, tendency to dissociate, fusion with thoughts, etc. Over time, Sally's developed coping mechanisms prevented her from attempting to make sense of her experiences. ${ }^{18}$

Let us further suppose there is no gap in the collective hermeneutical resources, but that Sally is

unable to access those resources owing to coping mechanisms. Importantly, Sally is not struggling to render her experience intelligible, so CASE 2 is not an instance of HI. However, it is plausible

CASE 2 exhibits HM. Moreover, there is a positive reason for treating CASE 2 as at least exhibiting

HM. Since Sally self-imposed coping mechanisms, rejecting CASE 2 as exhibiting HM seems close to victim blaming, ${ }^{19}$ i.e. claiming Sally is not hermeneutically marginalized, but perhaps inappropriately self-imposes coping mechanisms making her epistemically culpable. Of course, rejecting CASE 2 as HM does not entail characterization of Sally in a way that supports victimblaming. Still, it seems plausible if there is an alternative characterization of CASE 2 that does not so

\footnotetext{
${ }^{17}$ With these remarks we have identified hallmarks of HI sufficient to address (Medina, 2017a, pg. 41-2)'s remarks concerning hermeneutical death. Such scenarios do not exhibit MC and so do not exhibit $\mathbf{H I}$ as Fricker understands, though they perhaps exhibit some other form of epistemic injustice. These results shift the dialectical burden to Medina to provide reasons for thinking such scenarios should count as HI. Note, moreover, replacing $\mathbf{M C}$ with the weaker DC discussed in the preceding footnote provides no help here. Presumably, those exhibiting hermeneutical death lack relevant dispositions needed to participate in meaning-making and sharing practices. MC and DC both exclude hermeneutical death from counting as HI, as they both exclude CASE 1, though for different reasons.

${ }^{18}$ CASE 2 perhaps involves testimonial smothering (Dotson, 2012). For example, Sally might over time recognize that reflecting on the abuse she experiences inclines her to resist, which leads to further abuse. Sally may instead focus on minimizing the abuse, i.e. 'walking on eggshells', catering to Mike, etc. CASE 2 exhibits more than testimonial smothering, however, since Sally - after developing the relevant coping mechanisms - eventually does not reflexively silence based on assessment of her audience. We might refer to this phenomenon as hermeneutical smothering, identifying testimonial smothering carried to the point of unreflective habit as one route to this injustice.

${ }^{19}$ (Jenkins, 2016, pg. 10) makes a similar point involving rape/abuse myths as confounding hermeneutical resources.
} 
easily lend itself to such a reading, then we should prefer that alternative. I will thus assume our task in what follows is to discover how to classify CASE 2 as exhibiting $\mathbf{H M}$ while remaining consistent with Fricker's commitments.

Yet, there may be reasons to think CASE 2 does not exhibit HM. Fricker claims one cannot simply “opt in" (Fricker, 2006, pg. 153) to HM, e.g. become a hermit. Sally self-imposing coping mechanisms seems rather close to opting in. But Sally is not simply opting into HM. Sally is coerced into developing coping mechanisms. The importance of coercion to $\mathbf{H M}$ is supported by observing Fricker claims in cases of $\mathbf{H I}$ - and so $\mathbf{H M}$ - the absence of resources needed for mutual understanding of harmful experiences is not accidental, ${ }^{20}$ suggesting coercion is involved in $\mathbf{H I}$. And since $\mathbf{H I}$ is a structural phenomenon (Fricker, 2007; Fricker, 2016), lacking obvious perpetrators in paradigm cases, it is plausible to locate this "local marshalling of forces against attempts to render intelligible harmful experiences" in the background conditions against which $\mathbf{H I}$ manifests, i.e. HM. If correct, we should expect to find coercion associated with $\mathbf{H M}$ too.

We can appeal to Fricker's recent discussion of the potential overlap between $\mathbf{H I}$ and White Ignorance (Fricker, 2016, pg. 174-5) for guidance here. The relevant case Fricker examines for our purposes is (Fricker, 2016, pg. 174-5):

IGNORE: Non-culpably ignorant white people in an environment where hermeneutical resources have been suppressed and knowledge cannot be accessed as population lacks needed concepts for acquiring this knowledge.

Fricker claims IGNORE exhibits both white ignorance and HI. But note, if coercion alone were sufficient for $\mathbf{H M}$, then it is plausible members of the relevant white population might also be subjected to $\mathbf{H M}$ too, since it is not difficult to imagine, say, the suppression of relevant concepts and knowledge needed to understand the experiences of marginalized individuals is coerced, e.g.

20 “...the whole engine of collective social meaning was effectively geared to keeping these obscured experiences out of sight." (Fricker, 2007, pg. 153). In other words, HI is not a matter of bad luck or accident. 
through education, parents, propaganda, etc. Even under such conditions, however, it seems incorrect to say the ignorant members of the white population are subject to $\mathbf{H M}$. This suggests a way to understand the role of coercion in Fricker's account of HI. While ignorant white individuals in the relevant cases do not exhibit $\mathbf{H M}$, they exhibit Hermeneutical Disadvantage (HD), i.e. a deficit in subjects' abilities to contribute to collective epistemic resources (Fricker, 2016, pgs. 173-5): ${ }^{21}$

HM-HD If case $C$ exhibits $\mathbf{H M}$, then $C$ exhibits $\mathbf{H D}$ In addition to $\mathbf{H D}$, ignorant whites in these cases also exhibit significant Hermeneutical Advantage $\mathbf{H A}$, i.e. a surplus in subjects' abilities to contribute to collective epistemic resources. HA alone is insufficient to show a case does not exhibit $\mathbf{H M}^{22}$ since groups often exhibit both $\mathbf{H A}$ and $\mathbf{H D}$. What seems crucial to determining whether $\mathbf{H M}$ is exhibited is the ratio of quantity/quality of $\mathbf{H A}$ to $\mathbf{H D}$. We need not attempt to make this precise. ${ }^{23}$ Let $\mathbf{P}$ denote a quantitative and qualitative combination of $\mathbf{H A}$; let $\mathbf{Q}$ denote a quantitative and qualitative combination of $\mathbf{H D}$; let $\mathbf{T}$ denote some fixed positive real number. It suffices to say a case counts as $\mathbf{H M}$ with respect $\mathbf{H A}$ and $\mathbf{H D}$ if $\mathbf{T}<\mathbf{P} / \mathbf{Q}$, and a case does not count as $\mathbf{H M}$ if $\mathbf{T}>\mathbf{P} / \mathbf{Q}$. In other words, in a given context, a case counts as $\mathbf{H M}$ if the hermeneutical advantages weighed against disadvantages results in a number below a certain threshold which - perhaps - allows for indeterminate or borderline cases. So, ignorant white individuals in IGNORE do not exhibit HM, since the ratio of advantages to disadvantages is plausibly greater than any reasonable specification of $\mathbf{T}$ and non-white individuals in IGNORE are plausibly more disadvantaged than they are advantaged, so there is $\mathbf{H M}$. Altogether: To exhibit HM, local marshalling of forces must play to the coerced disadvantage of a group. These

\footnotetext{
${ }^{21}$ See (Fricker, 2007, pgs. 151-2). Here we find room for (Simion, 2018)'s observation that privileged individuals may be treated unjustly and, moreover, hermeneutically disadvantaged, without expanding Fricker's characterization of $\mathbf{H I}$. ${ }^{22}$ Fricker approvingly cites (Medina, 2012, pg. 108) who argues convincingly that members of dominant groups are in some ways epistemically disadvantaged, even though they are clearly advantaged. Similarly, members of marginalized groups may have epistemic advantages, though they are clearly disadvantaged too. This strongly suggests HA does not undermine HM since otherwise marginalized groups would not exhibit the latter if they exhibit the former.

23I agree with Aristotle that one should only seek precision to the extent one's domain permits. Here we find a limit.
} 
observations provide an explanation for why CASE 2 exhibits HM: Sally is coerced resulting in a proportion of $\mathbf{H A}$ to $\mathbf{H D}$ below some reasonable specification of $\mathbf{T}$.

Fricker's discussion of White Ignorance reveals one more hallmark of $\mathbf{H I}$, illustrated by reflection on the following (Fricker, 2016, pg. 173):

DISBELIEF: Non-culpably ignorant white people in an environment where hermeneutical resources needed to make sense of harmful experiences exist in the collective hermeneutical resource, but have been suppressed, forgotten, or never learned.

Fricker claims members of the relevant marginalized population attempting to render their harmful experiences intelligible to ignorant members of the white population in DISBELIEF are not subjected to $\mathbf{H I}$ since the inability of the white individuals to make sense of these harm ful experiences stems from epistemically culpable behaviors, ${ }^{24}$ e.g. failing to infer from existing concepts needed conceptual resources to understand. Contrast this result with IGNORE - which exhibits HI - where marginalized individuals fail to render their experiences intelligible to white individuals due to a literal gap in the collective conceptual resources. This is to say, whether $\mathbf{H I}$ is present trades on whether communication or understanding breaks down due to needed concepts for comprehension being obscured or being absent. If the former, there is not $\mathbf{H I}$; if the latter, there may be $\mathbf{H I} .^{25}$

\subsection{Hallmarks of $\mathrm{HI}$}

Combining these observations provide necessary and sufficient conditions for $\mathbf{H I}$ :

SF-HI Case C involving agents $\mathrm{S}$ and S' exhibits $\mathbf{H I}$ just in case:

(1) C exhibits $\mathbf{H M}^{26}$

(2) S struggles to render a harmful experience intelligible to S'

(3) S' fails to understand S due to S' lacking conceptual resources

${ }^{24}$ (Fricker, 2016, pg. 173-5). This is, as Fricker puts it, a failure at the level of belief rather than conceptual resources.

${ }^{25}$ This hallmark weighs against (Jenkins, 2018)'s counting as HI cases where surplus hermeneutical resources concerning domestic abuse and sexual violence lead to victims experiencing difficulties in rendering these experiences intelligible to themselves or others. This is not to say these cases do not exhibit some other form of epistemic injustice, it is simply to suggest it is not $\mathbf{H I}$.

${ }^{26}$ Because $\mathbf{T}>\mathbf{P} / \mathbf{Q}$ and coercion is involved. 
(4) Gap in (3) is not due to epistemically culpable ${ }^{27}$ behaviors by either S or S'

Where S and S' may be the same individual, e.g. Carmita Wood; Sue in CASE 1. Having identified necessary and sufficient conditions for $\mathbf{H I}$, we turn next to explicating Fricker's proposed remedy to this injustice, which has received far less attention than the injustice.

\section{Explicating Hermeneutical Justice}

Fricker proposed Hermeneutical Justice $\mathbf{H J}$ - a cultivated virtue consisting of sensitivity to the hermeneutical difficulties marginalized speakers confront when attempting to render experiences intelligible to others - as a remedy to $\mathbf{H I} .^{28}$ Beyond characterizing $\mathbf{H J}$ as a cultivated virtue, little has been added to this initial presentation. In this section, I approach $\mathbf{H J}$ through the lens of moral and epistemic harms, independently motivate moral and epistemic principles underwriting responsibilities that may be magnified based on context, and argue attention to contextual elements influencing attribution of moral and epistemic responsibility provides an explanation for the significant responsibilities privileged individuals may have in conversations with marginalized individuals struggling to communicate harmful experiences.

\subsection{Moral Aspect of HJ: First Pass}

Fricker divides (Fricker, 2007, pg. 163-5) the harms of HI into primary (always present with the phenomenon) and secondary (often present with the phenomenon). The primary harm of $\mathbf{H I}$ is that agents are unable to render harmful experiences intelligible; secondary harms include practical consequences of the primary harm, e.g. doubting oneself, denial of unemployment claims, etc. Secondary harms may in term compound primary harms. $\mathbf{H J}$ is meant to remedy both primary and secondary harms. Indeed, understanding the harms of $\mathbf{H I}$ in this manner leads naturally to

\footnotetext{
${ }^{27}$ For example, not gathering easily accessible evidence, knowingly ignoring easily accessible concepts, etc.

${ }^{28}$ (Fricker, 2007, pg. 169). Virtuous listeners recognize relevant speakers are "struggling with an objective difficulty and not a subjective failing." (Goetze, 2018, pg. 88) emphasized HJ as a requirement for marginalized individuals attempting to render experiences intelligible to themselves, not just to others.
} 
observing a way to address the primary harm, namely, creating space in which marginalized individuals may safely engage in the difficult task of understanding and communicating relevant harmful experiences. And if $\mathbf{H J}$ adequately addresses the primary harm of $\mathbf{H I}$ then it is plausible to think the secondary harms will be addressed too. This is, broadly speaking, Fricker's characterization of $\mathbf{H J}$. At the same time, however, understanding harms associated with $\mathbf{H I}$ in terms of this dichotomy leads less naturally to reflection on what responsibilities individuals have to address primary and secondary harms, beyond merely cultivating good listening habits and - perhaps more importantly - leads less naturally to reflection on how responsible parties might address these harms. It is, moreover, no surprise Fricker does not examine in detail responsibilities of individuals while discussing $\mathbf{H J}$, since $\mathbf{H I}$ is a structural injustice often lacking individual perpetrators.

An alternative characterization ${ }^{29}$ of $\mathbf{H I}$ harms - as moral or epistemic - is both broader than the primary/secondary distinction Fricker indexes to $\mathbf{H I}$ and provides an obvious link to responsibility. In broad outline, moral harms are harms to an individual insofar as they are an autonomous moral agent, epistemic harms are harms to an individual insofar as they are a source or creator of knowledge, and the presence of either harm suggests the presence of some corresponding moral or epistemic responsibility. The utility of framing harms in this manner is best illustrated by examining how they both align with Fricker's understanding of $\mathbf{H J}$ while explaining what responsible parties can do to address $\mathbf{H I}$ more specifically than simply cultivating listening habits. So, we will do just that.

Specifically, in what follows we frame $\mathbf{H I}$ as both moral and epistemic harms, and consequently, understand $\mathbf{H J}$ as involving corresponding moral and epistemic responsibilities. Unfortunately, this framing alone does not get us far in understanding Fricker's $\mathbf{H J}$, since Fricker provides little specification of this putative remedy. Fortunately, we can make progress on the moral

${ }^{29}$ (Fricker, 2016) observes the moral and epistemic aspects of $\mathbf{H I}$ in various places. 
aspect by relying on recent literature (Beverley, 2016) supporting context-dependent principles underwriting widely accepted (Beverley \& Beebe, 2017) judgments of moral responsibility. Independent of Fricker's discussion of $\mathbf{H J}$ it seems the following is true:

NON-MALFEASANCE For agents S, S', context C, and action A: If A harms S' in $\mathrm{C}$ then $\mathrm{S}$ has a prima facie moral responsibility in $\mathrm{C}$ not to perform A

This hardly needs defending. We seem to have a default moral responsibility not to harm others, and whether we have such a responsibility appears to vary by context. If James learns that whenever he taps his feet in class it causes Sally tremendous pain, then James in this context plausibly has a moral responsibility to refrain from that behavior. In such a context, NON-MALFEASANCE applies to James. On the other hand, if James taps his feet to alleviate his own tremendous discomfort at having to sit in seminar, and this merely causes Sally slight discomfort, it seems plausible James does not have a moral responsibility to refrain. In this context, the responsibility adverted in NON-

MALFEASANCE does not apply to James. These observations suggest certain features of context are relevant to whether an agent has a moral responsibility in that context, namely, perceived degree of harm done by an action and cost to an agent for refraining from that action.

Judgments of moral responsibility vary with respect to other contextual features, often intimately tied to the preceding. For example, it seems mistaken to attribute moral responsibility to refrain from a given action to agents who are genuinely unable to refrain from that action. This suggests judgments that an individual is morally responsible for refraining from some action track whether the agent is perceived as able to refrain or not. ${ }^{30}$ Similarly, it seems mistaken to attribute moral responsibility to agents who are able to refrain from actions that cause harm to others, but

\footnotetext{
${ }^{30}$ Whether this intuition is general is an open question, though the present balance of evidence suggests most intuitively believe if an individual is responsible for some action then they can perform that action. See (Kurthy, Lawford-Smith, $\&$ Sousa, 2017) for recent empirical discussion.
} 
who are genuinely unaware that they are able to refrain from those actions. Related, agents who know they can refrain from such actions but who do not realize those actions are harmful to others also seem outside the scope of moral responsibility as codified in NON-MALFEASANCE. What these brief outlines of philosophical and empirical results defended elsewhere suggest is that judgments of moral responsibility are sensitive not only to perceived harm to individuals and cost to the potential bearer of responsibility, but also to the knowledge of the bearer's ability and bearer's knowing a given action is harmful.

Though NON-MALFEASANCE is motivated independently of Fricker's discussion of $\mathbf{H J}$, it is an easy fit. Presumably, each of us has a moral responsibility to refrain from, say, contributing to difficulties marginalized individuals have when attempting to communicate harmful experiences, since such contribution is often harmful. NON-MALFEASANCE, moreover, fits with Fricker's characterization of $\mathbf{H I}$ as structural, and so generating limited responsibility with respect to individuals. NON-MALFEASANCE does not exactly capture Fricker's characterization of HJ, however. Fricker (Fricker, 2012, pg. 259-60; Fricker, 2016) suggests HJ may also involve active dissemination of information concerning the causes of marginalization, e.g. implicit bias, and Fricker has adopted a "whatever works" approach to addressing structural marginalization (Fricker, 2010, pg. 166). NON-MALFEASANCE does not provide sufficient responsibility to underwrite active involvement in addressing the injustice.

\subsection{Moral Aspect of HJ: Second Pass}

Reflecting further on the preceding observations reveals the lines along which to motivate stronger moral principles. Each of the preceding contextual features may magnify moral responsibility across contexts, as again strongly suggested by recent philosophical (Beverley, 2016) and empirical research (Beverley \& Beebe, 2017) exploring patterns of judgments of moral responsibility. Consider, if James can save Sally's life by donating blood plasma, which has little cost to James, then it seems James has 
a moral responsibility to accept this minimal cost to himself to prevent a substantial harm to Sally. ${ }^{31}$ James thus appears to bear a responsibility to accept a minimal cost to himself to prevent great harm - independent of his involvement in generation of that harm - and this moral responsibility is more than simply refraining from engaging in a harmful action, i.e. more substantial than NON-

MALFEASANCE. On the other hand, if the only way James can save Sally's life is by sacrificing his own, then it does not seem James has a moral responsibility to do so, again suggesting judgments of moral responsibility are sensitive to tradeoffs of harms to individuals in relevant contexts. Adjusting harm from Sally's perspective follows a similarly predictable pattern. If Sally is simply congested, then it seems incorrect to say James has a moral responsibility to sacrifice his life or limbs to clear up Sally's mild illness. Indeed, it is questionable whether James has a moral responsibility to even, say, donate blood plasma for the same end despite it being a minimal cost. These observations strongly suggest various judgments of moral responsibility are underwritten by a principle stronger than NON-MALFEASANCE, codifying responsibility not simply to refrain from harmful actions, but to in fact provide aid to others in need.

The following - which we might think of as a magnification of NON-MALFEASANCE then appear to obtain in certain contexts:

BENEFICENCE For agents S, S', context $C$, and action A: If $A$ aids $S^{\prime}$ in $C$ then $S$ has a prima facie moral responsibility in $\mathrm{C}$ to perform $\mathrm{A}$

What counts as providing aid to another here is broad; it may include substantial investment of time and energy in the cultivation of virtuous listening skills, but it also might consist in simply directing those in need to experts better able to offer assistance. As before, judgments of moral responsibility to provide aid in various contexts appear sensitive to one's ability to provide that aid, one having

\footnotetext{
${ }^{31}$ This, moreover, seems to be the case independently of whether James is the cause of Sally's life-threatening condition. To be sure, if James is the cause of Sally's life-threatening condition, then he seems to have more of a responsibility to donate blood plasma.
} 
knowledge of one's ability to provide aid, and knowledge of the effects of that aid. If James's blood will clearly not affect Sally's health, then it seems he has no moral responsibility to provide it for her. Similarly, if James's blood will in fact save Sally's life, but neither he nor anyone else knows that, then it seems again he has no moral responsibility to provide blood plasma to that end. Same for rather artificial - contexts in which James's blood could save Sally's life and he knows this, but he is unaware Sally (or anyone else) needs or will need his blood plasma for that purpose.

Returning to $\mathbf{H J}$, note BENEFICENCE involves moral responsibility substantial enough, it seems, to underwrite taking action to disseminate information concerning recently observed harms associated with implicit bias (Fricker, 2016). In that respect, this principle fits better with Fricker's characterization of $\mathbf{H J}$. This fit becomes clearer when examining the sorts of conversational contexts Fricker targets in her discussion of HJ. BENEFICENCE appears to apply, say, to privileged listeners in circumstances in which marginalized speakers are attempting to render intelligible harmful experiences. Privileged listeners carry with them authority to validate or invalidate - broadly speaking - communicative attempts by marginalized speakers, as evidenced by Fricker's detailed exposition of testimonial injustice (Fricker, 2007), Doston's articulation of testimonial smothering, etc. (Dotson, 2011). Put another way, privileged conversational partners have the ability to help or harm marginalized speakers in relevant conversations. Moreover, moral harms associated with HI may be severe, undermining knowledge of oneself, affecting lives of loved ones, undermining autonomy, etc., and it appears in many contexts privileged listeners experience little cost in helping marginalized individuals understand harmful experiences. It is thus reasonable that privileged individuals listening to the difficulties marginalized speakers have in rendering harmful experiences intelligible are under at least a moral responsibility as strong as BENEFICENCE. This seems good motivation for understanding the moral aspect of $\mathbf{H J}$ in part along the lines of this stronger moral principle. 
There are, as one should expect, caveats. Consider, privileged listeners who are legitimately unaware of the abilities they have in conversation with marginalized speakers may not bear moral responsibility to provide aid along the lines of BENEFICENCE. This may appear a cost to the principle since that suggests BENEFICENCE does not apply in contexts where privileged individuals are ignorant. Given the prevalence of, say, white ignorance this might make

BENEFICENCE and the codified responsibility appear inapplicable in most contexts. To be sure, I think it is plausible BENEFICENCE does not apply to privileged individuals who are genuinely ignorant of their privilege and who are presented with marginalized speakers attempting to render intelligible harmful experiences. But most real-world contexts involve privileged individuals who have significant evidence that they are privileged, even in cases of white ignorance. True, privileged individuals are often motivated to disregard, ignore, or explain away such evidence, but they are nevertheless exposed to ample evidence of race, sex, disability, and age discrimination, among other forms. In that respect, they have reasons to suspect they bear privilege, insofar as they do not fall into such classes of individuals. Hence, they have reasons to suspect they bear such authority in conversation with marginalized individuals attempting to render harmful experiences intelligible. ${ }^{32}$ Privileged individuals with such ample evidence are within purview of BENEFICENCE, and this condition seems met in most contexts involving privileged individuals.

One might grant the preceding but remain concerned that privileged listeners in relevant contexts may be outside the scope of BENEFICENCE even if they recognize they are able to help marginalized speakers avoid serious harm at little cost to themselves. If privileged individuals do not

\footnotetext{
${ }^{32} \mathrm{My}$ own experience here feels relevant. I am white, grew up in Georgia, was quite poor, and lived in a trailer park with my extended family, most of whom were conservative, exhibited racist tendencies, and inclined to either distort or ignore evidence that they might be wrong about their beliefs. Even so, living near equally poor families comprised of marginalized individuals made it clear to even the worst offenders of my family that we had privilege. This was evident by, say, the differences between how, educators, police, etc. treated us. I have since lived - and still do - in more affluent environments, surrounded by privileged, educated, middle and upper class individuals. They also appear aware of privilege. This is not to say my experience exhausts all possibilities of ignorance. It is simply to say scenarios in which privileged individuals are entirely ignorant of their privilege seem - in my experience - rare.
} 
know bow to provide aid to marginalized speakers exhibiting $\mathbf{H I}$, it seems incorrect to say they nevertheless have a responsibility to provide aid. Indeed, privileged listeners may worry - rightly that they might do more harm than good, and since NON-MALFEASANCE plausibly applies to them in such contexts, they bear a responsibility to refrain from action that is harmful to the speaker. To be sure, privileged individuals in such contexts might stumble upon a way to provide just the right help to marginalized speakers in contexts exhibiting HI. But toy soldiers are toys, not soldiers, and accidental virtues, mere accidents. The risk of potential harm in such contexts seems too great to leave to chance. This suggests BENEFICENCE does not apply to privileged agents in such contexts. Rather, privileged individuals bear responsibility underwritten by BENEFICENCE when they have evidence of the efficacy of aid they attempt to provide. Unfortunately, this requirement sharply delimits the number of contexts in which privileged individuals bear responsibility to aid marginalized speakers exhibiting $\mathbf{H I}$, since it is plausible given the nature of $\mathbf{H I}$, many privileged individuals presented with a marginalized individual struggling to make sense of harmful experiences will - rightly - lack confidence in the efficacy of help they might provide.

In sum: Our independently motivated contextual principles NON-MALFEASANCE and BENEFICENCE appear to line up with Fricker's characterization of the moral aspect of $\mathbf{H J}$, yet the latter seems to exclude from responsibility agents who do not know how to provide aid effectively to those in need. Rather, given the potential harm one might expect arising from trying and failing to provide aid in such a scenario, and the force of NON-MALFEASANCE in such contexts, it seems agents should not, in fact, attempt to provide aid. What is needed to address this issue, it seems, is agents bearing a responsibility to learn to provide aid in future contexts. This, moreover, seems needed to capture Fricker's choosing to describe $\mathbf{H J}$ as a cultivated virtue (Fricker, 2007). Virtues take time to develop, and cultivating virtue often involves intentional, deliberative, learning. 


\subsection{Moral Aspect of HJ: Third Pass}

We make some progress by again reflecting on the above contextual features which influence judgments of moral responsibility. Privileged individuals who recognize they lack skills needed to provide aid to marginalized speakers in such contexts, gain evidence of an educational gap. This evidence, coupled with awareness of authority one has to (in)validate marginalized speakers in conversational contexts, and awareness of the significant harms associated with $\mathbf{H I}$, creates a somewhat rare context for the privileged individual, and it has been shown judgments of moral responsibility are sensitive to rarity of provider's ability to offer aid (Beverley, 2016; Beverly \& Beebe, 2017).

Consider, Rhesus disease kills millions of infants around the world, and there is - at present - not a cure that can be synthesized in a lab without the blood plasma of John Harrison. Harrison's donations have saved the lives of approximately 2.4 million infants worldwide. It seems plausible he has a responsibility to donate. But it also seems Harrison is uniquely ${ }^{33}$ positioned to help, and this carries great responsibility to do so. To see this, consider if each of us knew we were able to provide blood plasma that could be used to synthesize a vaccine for Rhesus disease, but none of us donated, then we would have all done something morally wrong, but none of us would have obviously done anything worse than anyone else in this context (Beverley, 2016). In contrast, in our context where John Harrison is uniquely able to provide this aid and is aware of that fact, John refraining from donating blood plasma seems morally worse than it would be in the context where everyone himself included - could donate but decided not to. Perceived rarity to provide aid thus seems to influence judgments of moral responsibility, and as with other features of contexts discussed, this influence has been supported empirically.

${ }^{33}$ This implies luck influences responsibility, which is contentious (McMahon, 2002), though see (Beverley, 2016). 
Since it seems rarity magnifies moral responsibility generally speaking and privileged individuals in contexts exhibiting $\mathbf{H I}$ who realize they are ill-equipped to provide aid find themselves in a rare position to help, there seems motivation for a moral responsibilities beyond that found in BENEFICENCE, namely, to learn to provide aid. We might characterize this as:

MORAL EDUCATION For agents S, S', S', and contexts C, C': If S' needs aid in $\mathrm{C}$ and $\mathrm{S}$ does not know how to provide that aid in $\mathrm{C}$, then $\mathrm{S}$ has a prima facie moral responsibility to learn how to provide such aid to relevantly similar agent $S$ ” in similar context C'

With MORAL EDUCATION, we have an explanation based on contextual features for agents having a moral responsibility to learn to provide aid to others in various contexts. In particular, we have an explanation for privileged individuals in contexts exhibiting $\mathbf{H I}$ having a moral responsibility to cultivate virtuous listening skills, among others. This much aligns with Fricker's brief characterization of $\mathbf{H J}$. Still, we might nevertheless worry that moral responsibility codified in MORAL EDUCATION is too easily undermined. Even if we fix contextual features so that privileged individuals in contexts exhibiting $\mathbf{H I}$ are aware of their own privilege and associated abilities to help, are confident in those abilities, and recognize how helpful they can be, there is still the question of cost to the provider. This is worrisome not because learning to provide efficacious aid to marginalized speakers in such contexts would itself be a great cost to privileged individuals, but because it seems it may in many cases be just costly enough to undermine responsibility given the fact that each of us have various projects, life goals, etc. that should be considered when evaluating overall cost. A privileged individual devoting most of her life to finding a cure for cancer, while raising a family, volunteering at various causes, practicing yoga for mental health, etc., might find little time to effectively learn to and develop confidence in providing aid to marginalized individuals in contexts exhibiting $\mathbf{H I}$. Learning to provide aid to marginalized speakers in such 
contexts may not be a negligible investment when weighed against other investments one has; as a result, the tradeoff between costs to oneself and benefits of providing aid to others might result in the responsibility adverted as applying to privileged individuals in MORAL EDUCATION being overridden in such contexts.

How forceful this worry ultimately is depends largely on judgments of how costly education and practice is to a potential privileged provider. This in turn depends on how much time and effort learning strategies for providing aid in such context takes. Depending on the context, it may be a simple as learning to listen attentively, asking questions to keep conversation flowing, recognizing and attending to silences, or directing marginalized individuals to experts better able to help. In other contexts, in contrast, it may be as complicated as developing skills often found among clinical psychologists. At this point, I can only offer my intuition that privileged individuals in the former contexts more often than not bear the responsibility adverted in MORAL EDUCATION, while those in the latter - unless they, in fact, are clinical psychologists - do not obviously bear such substantial responsibilities. ${ }^{34}$ We revisit how moral and epistemic responsibilities may be magnified in institutional contexts in some detail below, but before then we turn to the epistemic aspect of $\mathbf{H J}$ to provide a full picture of the putative remedy for $\mathbf{H I}$.

\subsection{Epistemic Aspect of HJ: First Pass}

Fricker's initial presentation of $\mathbf{H J}$ provides a starting point for reflections on contextual features relevant to epistemic responsibility, though it seemed little more than a species of the sort of epistemic responsibility each of us already owes to one another:

SUSPEND For agents $S, S^{\prime}$ in context C: If $S^{\prime}$ is having trouble articulating an experience, argument, counterexample, etc., to $\mathrm{S}$, then $\mathrm{S}$ has a prima facie

\footnotetext{
${ }^{34}$ Empirical work - which is currently in progress - is needed to examine how general the appealed to intuition is.
} 
epistemic responsibility to refrain from inferring $S$ ' is confused, nonsensical, etc.

Insofar as one intends to engage in conversation with another, SUSPEND seems true. This is not, of course, to say we each have a responsibility to assume struggling interlocutors are never confused, nonsensical, etc. Indeed, in some cases it seems we should make such assumptions, e.g. students having trouble articulating questions about difficult philosophical material. Further, reflecting on differences between contexts in which this principle applies and when it does not reveals contextual features relevant to judgments of epistemic responsibility. To sharpen the analysis, focus on contexts where the speaker is attempting to, say, articulate an experience to themselves. As an example of a context in which the principle plausibly applies, consider a physicist encountering data suggesting a well-confirmed physical theory is false. This physicist would - rightly - be reluctant to immediately jettison the theory, but may nevertheless have difficulty explaining the new data; it seems incorrect to count them as confused or nonsensical, suggesting the responsibility adverted in SUSPEND applies to the physicist in this context. On the other hand, as an example of a context in which the principle does not seem to apply, consider an individual raised in a racist environment who acquires evidence that conflicts with his racist ideology. This individual might also struggle to make sense of this new evidence given his existing beliefs; but here it seems correct to count this individual as confused or nonsensical, suggesting the responsibility adverted in SUSPEND in this context is overridden. Roughly speaking, the epistemic difference between these cases seems to depend on a tradeoff between evidence one has for a set of beliefs that typically get the right results, and the amount and extent of counterevidence to those beliefs. A well-confirmed physical theory met with minimal counterevidence seems worth holding on to; racist beliefs learned from one's environment are more frequently met with counterevidence than such physical theories. 
This tradeoff between contextual features influencing judgments of epistemic responsibility can be illustrated further by reflecting on a childhood anecdote shared by W.E.B. Du Bois (Du Bois, 1903, pg. 16) which suggested an early struggle to understand why white children treated him differently. In this brief story, Du Bois suggests having considered several explanations for this different treatment, e.g. he was not as smart as other children, he was not as athletic, etc., and having formed such hypotheses, he tested them, e.g. attaining academic excellence, becoming a star athlete, disconfirming each. Ultimately, Du Bois concluded he was treated differently due to the color of his skin, given so many other putative explanations failed. Important for our purpose, is how epistemically responsible it would seem - at least initially - for Du Bois to attempt to explain why white children treated him differently based on obvious, available metrics, e.g. athleticism, intelligence, which no doubt often provided adequate explanations for differential treatment he witnessed among and between white children. These metrics likely seemed adequate for many purposes and confirmed to that extent. Du Bois on this reading is not - at least initially - concluding from his struggles that he is confused or nonsensical. Of course, Du Bois eventually acquired sufficient evidence suggesting these metrics were inadequate, at which point it seems plausible to say that he - as a matter of fact - was confused and realized this was so. This confusion, however, owed to inculcation into widespread privileged norms that circumscribed and emphasized certain explanations for experiences over others. In contexts with such mounting counterevidence to his previous beliefs, Du Bois no longer had an epistemic responsibility to refrain from considering himself confused, at least with respect to the beliefs and explanations he left behind. And this realization of confusion gave way ${ }^{35}$ to adequate understanding of his experiences employing an explanation based on color divisions, an explanation notably neither obvious nor widely available in

\footnotetext{
${ }^{35}$ See (McAdams, 2015) and other personality research who explore the importance of understanding one's life as a coherent and cohesive narrative, often involving re-evaluation of life events.
} 
his environment. Again, this suggests judgments of epistemic responsibility are sensitive to tradeoffs between confirmations of one's, say, beliefs and counterevidence to those beliefs. ${ }^{36}$

Returning to $\mathbf{H J}$, initially presented the epistemic aspect of this phenomenon seems simply a specific instance of SUSPEND involving privileged and marginalized interlocutors. While interpreting $\mathbf{H J}$ in this manner fits comfortably with Fricker's insistence that $\mathbf{H I}$ - a structural injustice - does not have epistemically culpable perpetrators, understanding $\mathbf{H J}$ in only this manner simply amounts to a reminder that we should be better communicators with respect to marginalized individuals. To be fair, given the prevalence of $\mathbf{H I}$, there is value in emphasizing $\mathbf{H J}$ even if it is little more than SUSPEND. Still, one might expect a more robust remedy to HI. As when examining the moral aspect, attention to contextual features which appear to influence judgments of epistemic responsibility motivates more substantial epistemic responsibilities in contexts exhibiting $\mathbf{H I}$.

\subsection{Epistemic Aspect of HJ: Second Pass}

Specifically, more substantial epistemic responsibilities than those found in SUSPEND apply to privileged individuals in cases exhibiting $\mathbf{H I}$ because they have much to gain - epistemically speaking in precisely these contexts (Medina, 2017a; 2017b). As argued by Medina, among others, marginalized individuals provide insight into epistemic blind-spots, meta-resistance, etc. learning of which would be epistemically beneficial for non-marginalized individuals. It is plausible that in contexts where privileged individuals may reap significant epistemic benefits, they have greater epistemic responsibility than that adverted in SUSPEND. Medina (Medina, 2017b, pg. 48) has suggested a preliminary list of critical reflective capacities and strategies virtuous listeners exhibiting HJ might employ, e.g. recognize when to remain silent, suspend judgment about another's intelligibility, listen for silences, let others set discussion dynamics, etc. which may result in such

\footnotetext{
${ }^{36}$ As an aside, this story also suggests crucial points of recognition of confusion leading to deeper understanding of one's experiences, might track whether (E-NRM) applies across context. We do not pursue that here.
} 
epistemic benefits. And some of Medina's suggestions seem motivated independent of contexts exhibiting HI. Suppose a graduate student meets with his dissertation committee chair to brainstorm an idea for a dissertation chapter. ${ }^{37}$ If the advisor - an expert in the relevant field - immediately offers a rather complete suggestion and attempts to begin working through the details of the idea with the student, this might - rightly - upset the student, who may feel they came to a meeting intending to brainstorm and share their own ideas, but is now in a position where they feel compelled to either engage with the advisor's detailed idea or explain why they do not want to engage with the suggestion. Either way, it seems in such a context alternative ideas are obscured in part due to, say, the completeness of the advisor's suggestion, the epistemic authority of the advisor as a source of knowledge, and the conversational setting. Such an outcome might have been avoided had the advisor let the student set the conversational agenda, noticed the student's silence or discomfort if there was either, etc.

The potential for obfuscation is magnified when marginalized speakers are addressing those with privilege. Suppose Du Bois had confided in a white advisor who proceeded to offer plausible, coherent, explanations for the behavior of the white children, such as those Du Bois himself actually considered. It is plausible such explanations might have carried more weight coming from outside, and in particular from a white adult advisor, and so may have caused Du Bois serious epistemic harm insofar as they obscured the more likely explanation from consideration. Du Bois would have found himself defending why these alternative explanations were inadequate, rather than seeking out an alternative to these suggested alternatives. Here we have epistemic authority combined with plausible, complete, rather widespread explanations for a harmful experience, which obscure exploration of alternative explanations.

\footnotetext{
${ }^{37}$ Many thanks to Hollen Reischer for assistance in thinking through the consequences of this example.
} 
We might codify Medina's independently motivated suggestions in the following principle, capturing a more robust epistemic responsibility than that found in SUSPEND:

CHARITY For agents S, S' in context C: If S' is having trouble articulating an experience, argument, counterexample, etc., to $\mathrm{S}$ in $\mathrm{C}$, then $\mathrm{S}$ has a prima facie epistemic responsibility to employ virtuous listening strategies

Much as with BENEFICENCE, this principle does not address contexts in which agents lack the needed skills. Fortunately, in this case the stronger principle appears motivated already, given the epistemic benefits of rooting out blind spots and meta-resistance. That is, assuming a privileged individual lacking virtuous listening skills is aware that contexts involving $\mathbf{H I}$ might be opportunities to reap significant epistemic benefits in the form of identifying and overcoming epistemic blind spots and meta-resistance, they have an epistemic responsibility to acquire those virtuous listening skills for use in similar future contexts.

\subsection{Epistemic Aspect of HJ: Third Pass}

One might worry requiring privileged listener awareness - in contexts exhibiting $\mathbf{H I}$ - of opportunities to overcome epistemic blind spots and meta-resistance, is too restrictive (Medina, 2013). Epistemic blind spots for our purposes arise when privileged individuals either do not see certain evidence of the existence of marginalization as actually evidence of marginalization (Medina, 2013, pg. 66). Meta-resistance understood here amounts to privileged individual difficulties in recognizing they have blind spots (Medina, 2013, pg. 66-69). The worry is that the very nature of epistemic blind spots and meta-resistance makes such awareness difficult. This in turn might undermine any epistemic responsibility many privileged individuals might have to cultivate virtuous listening skills for use in relevant contexts. Du Bois appears to provide an example of the possibility of overcoming meta-resistance and recognizing epistemic blind spots, and examining this success sharpens the concern with respect to privileged individuals. Du Bois experienced harm resistant to readily available explanations, leading to recognition of an epistemic blind spot and adoption of an 
alternative perspective through which to understand his experience. But this success depended largely - it seemed - on failures to make sense of harmful experiences given dominant, readily available, cultural resources. In contrast, the white children in his environment likely felt no need to appeal to explanations for their experiences outside those readily available in dominant, prevalent, cultural norms at the time. This might suggest privileged individuals often will not recognize contexts exhibiting $\mathbf{H I}$ as opportunities to overcome epistemic blind spots, indeed perhaps due to those very blind spots. If so, CHARITY seems inapplicable to privileged individuals in such contexts.

At this point, many have suggested strategies and tactics for providing sufficient evidence to privileged individuals with epistemic blind spots exhibiting meta-resistance, e.g. (Medina, 2017a; 2017b) suggests we engage in hermeneutical friction and sometimes respond to micro-aggression with counter micro-aggression, (Lorde, 1981) suggests a plausible use of anger along similar lines, etc. These suggestions aside, it seems nevertheless plausible privileged individuals with such blind spots and meta-resistance have sufficient evidence of these epistemic problems to bear responsibility. Indeed, focusing on the evidence privileged individuals in, say, the present U.S., it is hard to see how most do not have sufficient evidence of blind spots and meta-resistance to recognizing them. Simply put, there is enough of a predictable pattern of marginalized individuals already exhibiting anger, claiming privileged individuals have blind spots and exhibit meta-resistance, and discussion of harms stemming from discrimination, throughout the history of this country to suggest the presence of both epistemic blind spots and meta-resistance among privilege individuals. ${ }^{38}$ Moreover, it is a short step from recognition of the possibility of epistemic blind spots and metaresistance concerning issues of marginalization, to recognizing opportunities to overcome these

\footnotetext{
${ }^{38}$ Expressions implicit in this discussion such as "Sam recognizes an epistemic blind spot" are ambiguous between de dicto and de re recognition readings, i.e. "Sam is such that he recognizes an epistemic blind spot" vs "There is some epistemic blind spot such that Sam recognizes it." I have in mind here the former, de dicto recognition, reading.
} 
epistemic problems in discussion with marginalized individuals. This is all to say, one might worry CHARITY is too restrictive since application requires privileged individuals be aware of epistemic blind spots and meta-resistance, but it seems most privileged individuals in our present society have ample evidence suggesting the presence of such epistemic problems, and so CHARITY seems - as a matter of fact - applicable in such contexts.

Moreover, once this concern over constraints on CHARITY is removed, given the obvious benefits one might acquire in overcoming epistemic blind spots and meta-resistance, it seems plausible relevant individuals have an epistemic responsibility to learn skills that might assist in overcoming such epistemic problems. Restricting attention to scenarios that might exhibit $\mathbf{H I}$, the following principle seems supported:

EPISTEMIC EDUCATION For agents S, S', and contexts C: If S' is having trouble articulating an experience, argument, counterexample, etc., to $\mathrm{S}$ in $\mathrm{C}$ and $\mathrm{S}$ does not have critical reflective capacities or virtuous listening strategies to employ, then $\mathrm{S}$ has a prima facie epistemic responsibility to cultivate such virtues and capacities in the interest of employing them in when engaged with relevantly similar agents and contexts

As with the moral principles discussed earlier, we can understand the relationships among SUSPEND, CHARITY, and EPISTEMIC EDUCATION in terms of context-sensitivity, where the first provides a base epistemic responsibility sensitive to and so potentially magnified by tradeoffs between evidence and counterevidence, as well as potential epistemic gains associated with the context.

\subsection{Combining Moral and Epistemic Aspects of $\mathrm{HJ}$}

With these epistemic principles, we seem close to what Fricker appears to have in mind by suggesting $\mathbf{H J}$ involves cultivation of virtuous listening strategies. Indeed, combining these 
principles with NON-MALEFEASANCE, BENEFICENCE, and MORAL EDUCATION

provides an independently motivated explication of both the moral and epistemic aspects of $\mathbf{H J}$, which offers a general explanation for judgments of moral and epistemic responsibilities we seem to have in scenarios exhibiting HI. Privileged individuals in contexts exhibiting $\mathbf{H I}$ plausibly either bear moral and epistemic responsibilities to employ strategies to aid marginalized speakers, or moral and epistemic responsibilities to learn such strategies and cultivate associated virtues. Moreover, appealing to such contextual features allows a clear distinction between moral and epistemic of responsibility in relevant contexts. An avowed racist may recognize the epistemic benefits of helping marginalized individuals render harmful experiences intelligible, since this may provide insights into epistemic blind spots, meta-resistance, etc., but they may engage in this behavior in an effort to sustain those blind spots, etc., in others. That is, they might develop and employ virtuous listening strategies for immoral purposes. Such an individual would align with the above epistemic responsibilities while failing to satisfy the moral responsibilities.

We turn next to resistance one might have in adopting these principles, replies, and two applications which strengthen the case for adopting them.

\section{Objections, Replies, and Proof of Concept}

Much of the substantial responsibilities discussed thus far seem compatible with Fricker's characterization of $\mathbf{H J}$. That said, one might worry these principles may underwrite more substantial responsibilities than Fricker is inclined to attribute, given $\mathbf{H I}$ is understood to be largely a structural problem. I argue Fricker should adopt these principles in any event. In addition to offering a clear explanation of responsibility in various contexts and being independently motivated, these principles largely align with what little Fricker suggests concerning $\mathbf{H J}$, and potentially provide responses to criticisms that Fricker's characterization of $\mathbf{H J}$ is too individualistic to address structural injustices like HI. Moreover, as proof of concept, I examine how these principles make sense of Fricker's 
commitment to sometimes significant institutional responsibilities, how individuals may bear substantial responsibilities to address injustices, and how marginalized individuals may not bear responsibilities to educate privileged interlocutors.

\subsection{Resistance to Substantial Responsibility}

Fricker should grant principles at least as strong as SUSPEND and NON-MALFEASANCE underwrite $\mathbf{H J}$, but also that in contexts exhibiting $\mathbf{H I}$, these principles may be magnified and consequently may generate significant epistemic and moral responsibilities for privileged listeners exposed to communicative attempts by marginalized speakers. However, Fricker might protest adopting, say, some combination of CHARITY, BENEFICENCE, EPISTEMIC EDUCATION, and MORAL EDUCATION runs the risk of imposing too much responsibility on individuals who are perpetuating the structural injustice of $\mathbf{H I}$, but who are not themselves obviously culpable. In addition to the reasons provided in the previous section, there are at least two further reasons for Fricker to adopt this proposal. First, Fricker provides conceptual space for great responsibility in certain contexts, ${ }^{39}$ by claiming agents might be morally/epistemically responsible for behaviors even if they are not blameworthy for those behaviors. An individual, for instance, who takes great precautions against implicit bias, whose behavior is nevertheless non-culpably influenced by such bias, upon realization of the subsequent harms stemming from the associated harmful behavior, is not blameworthy - Fricker urges - but is responsible for that behavior. Fricker suggests regret the individual might feel, and later actions that individual might take to prevent engaging in similarly harmful behavior, are best described by recognition of responsibility, even absent blame. This suggests room for attributing perhaps significant responsibility in certain contexts, in accordance with principles stronger than SUSPEND and NON-MALFEASANCE, even absent

${ }^{39} \mathrm{I}$ have in mind (Fricker, 2016)'s discussion of agent-regret. 
blame. ${ }^{40}$ For even epistemically innocent privileged individuals are often in positions of relative power when communicating with members of marginalized groups, and this is particularly true when the latter are struggling to render harmful experiences intelligible to the former. Whether they are or are not at epistemically or morally blameworthy is beside the point; plumbers fix leaks because they can, not because they cause the leak.

Second, $\mathbf{H J}$ is meant to address $\mathbf{H I}$, but as discussed in Section 2, the latter phenomenon is a symptom of an underlying disease, namely, HM. Absent some way of treating the disease, it seems likely the symptoms will continue to manifest. Fricker seems aware $\mathbf{H J}$ should in some way address HM. She claims (Fricker, 2007, pgs. 154) with enough instances of $\mathbf{H J}$ addressing instances of $\mathbf{H I}$, even the underlying $\mathbf{H M}$ will be remedied. This proposal has been met with several criticisms (Dotson, 2011; Medina, 2013). Simply put, the problem is that $\mathbf{H M}$ is structural and resistant to change if limited to the cultivation of individual virtues underwritten by principles as minimal as SUSPEND and NON-MALFEASANCE; indeed, if Fricker's proposed remedy to $\mathbf{H I}$ is to treat more than merely the symptoms of the disease, then more substantial responsibility should be expected at the level of individuals. ${ }^{41}$ The context-sensitive epistemic and moral principles defended here seem fitting in this respect, and to that extent should be accepted by Fricker as constitutive of

\footnotetext{
${ }^{40} \mathrm{I}$ take these principles to support (Fricker, 2016)'s claim that epistemic agent-regret may play a motivational role when, say, an epistemically blameless writing-sample assessor is motivated to change future behaviors having gained new evidence that previous complacency was harmful, i.e. new evidence her behaviors conflict with BENEFICENCE and CHARITY.

${ }^{41}$ For example, Fricker's suggestion that localized virtues engender structural change has been criticized as misguided (Anderson, 2012), and her general theory of epistemic injustice accused of overlooking and perhaps perpetuating injustices worth addressing (Polhaus, 2012). Additionally, one might worry HJ is insufficient, practically speaking, to address $\mathbf{H I}$ given the substantial resistance privileged individuals exhibit when confronted with their ignorance. (Mills, 2007)'s careful study of "white ignorance" and (Medina, 2017)'s subsequent generalizations to "meta-resistance" and "meta-ignorance" provide grist for this mill. Borrowing (Nguyen, 2019)'s terminology, we might characterize privileged individuals as often inhabiting echo chambers rather than echo bubbles, the latter popped by simply adding new counter evidence.
} 
$\mathbf{H J}$. The principles and responsibilities codified in them are broader than $\mathbf{H I}$, and so may extend beyond $\mathbf{H J}$ to address the underlying conditions. ${ }^{42}$

\subsection{Proofs of Concept}

Two further applications of the epistemic and moral principles I claim should be constitutive of $\mathbf{H J}$ strengthen the case. Observe, Fricker (Fricker, 2012) is amenable to extensions of $\mathbf{H J}$ in institutional contexts in which clinical psychologists treat patients, marginalized or otherwise. Specifically, Fricker includes under the purview of $\mathbf{H J}$ agents inhabiting institutional roles carrying significant responsibilities comparable those codified in CHARITY, BENEFICENCE, EPISTEMIC EDUCATION, and MORAL EDUCATION, such as investing time to build trust, guiding patients towards understanding cognitive dissonance, and the importance of struggling to render harmful experiences intelligible to oneself. The fact that clinical psychologists willingly enter into these roles with the purpose of aiding others, coupled with Fricker's willingness to accept such agents may have substantial responsibilities to aid their clients, motivates accepting magnifications of the context-sensitive principles underwriting $\mathbf{H J}$, associated with institutional roles:

MORAL PROFESSIONAL Agent $S$ in role $R$ in institutional context $C$ has a prima facie moral responsibility to aid others through fulfillment of potentially substantial responsibilities associated with $\mathrm{R}$ when $\mathrm{S}$ can do so

And:

EPISTEMIC PROFESSIONAL Agent $\mathrm{S}$ in role $\mathrm{R}$ in institutional context $\mathrm{C}-$ often therapeutic in nature - has a prima facie epistemic responsibility to actively address behavioral cues correlated with known signals of coping mechanisms observed in clients who may

\footnotetext{
${ }^{42}$ The force of this suggestion, of course, depends on whether and to what extent one can uncover moral and epistemic features of contexts sufficiently magnifying needed responsibilities to generate, say, collective epistemic and moral responsibilities. I take this to be a natural next step of the analysis, but unfortunately do not have the space to engage in that extraction here.
} 
be disinclined to attempt to render harmful experiences intelligible

The moral harms prevented in relevant contexts seem sufficient to motivate MORAL

PROFESSIONAL while the epistemic benefits (Beverley \& Reischer, 2019; Reischer \& Cowan, 2020). clinical therapists might acquire through such training and how those benefits align with occupational role goals, strongly suggest EPISTEMIC PROFESSIONAL applies as well. And with these principles in mind as targets, we might even extend responsibility outside of institutional roles to cases of mere $\mathbf{H M}$ in certain contexts. ${ }^{43}$ For example, in CASE 2 - which exhibited $\mathbf{H M}$ but not HI owing to the fact that Sally did not attempt to render her experiences intelligible to herself or others - we might expect $\mathbf{H J}$ as a partial remedy. ${ }^{44}$ And given the significant harm Sally experiences in this case, it seems plausible more than the rather limited SUSPEND and NONMALFEASANCE would apply to clinical psychologists working with Sally. This is precisely what one should expect; for it is unclear how waiting to interpret a marginalized speaker charitably would be helpful if they are not inclined to speak at all. What seems needed is not just virtuous listening, but attention to behavior correlated with cognitive coping mechanisms, e.g. anxiety, inability to maintain long-term relationships, substance abuse, etc. Relatedly, institutional roles aside, it seems plausible family and friends occupy roles sufficient to ground responsibilities more substantial than CHARITY, EPISTEMIC EDUCATION, BENEFICENCE and MORAL EDUCATION, but even if one is skeptical about attributing such significant responsibility to these individuals, they at least seem to bear a responsibility to direct Sally to experts better equipped to help. Moreover, I

\footnotetext{
${ }^{43}$ For example, these principles would accommodate Medina's hermeneutical death with respect to treatment. ${ }^{44}$ I agree with Medina that fighting $\mathbf{H I}$ requires hermeneutical resistance, though he focuses largely on justification for deployment of insurrection strategies in cases of epistemic death.
} 
suspect they would implicitly acknowledge such responsibility to do so if, as seems a plausible thought, they ever wished they knew how they might help Sally. ${ }^{45}$

Consider next ${ }^{46}$ an application of these moral and epistemic principles to marginalized individuals confronted with privileged individuals unable to understand marginalized experiences. This is a case of what Fricker calls minimal-HI, where the conceptual gap in the collective hermeneutical resources owes to speaker and listener operating with non-overlapping conceptual resources. Above, we focused on the perspective of privileged individuals to motivate epistemic and moral responsibilities. Of the former sort, we urged that privileged individuals had much to gain epistemically speaking, by engaging with marginalized individuals since this might uncover blind spots and meta-resistance. But we should take care not to venture into epistemic exploitation in such scenarios (Bernstein, 2016). Marginalized listeners knowingly able to help privileged individuals render their own harmful experiences intelligible do not necessarily have a responsibility to do so. Specifically, if assisting in this manner makes marginalized listeners more vulnerable to exploitation, oppression, discrediting, etc., then the costs to provide aid seem too high to correctly claim a moral responsibility to provide that aid (Medina, 2013, pg. 116; Baldwin, 1979). In such contexts the tradeoff between benefits provided and costs to the provider seems paramount, and sufficient in many cases to override even the rarity of a given marginalized individual in a given conversation to educate a privileged individual. For marginalized individuals have much evidence that such assistance is often ineffective, underappreciated, and liable to generate harmful stereotypes, among

\footnotetext{
${ }^{45}$ These remarks concerning responsibilities associated with roles extend across important areas of social life. Physicians, for example, bear robust responsibilities when treating patients, overlapping those outlined in the preceding sections. Similarly, lawyers discharging various duties acquire extensive responsibilities to help others, as do police officers and members of the military. Each of these offices involves nuance worth exploring with respect to responsibilities, but what seems common to each is robust responsibility to help themselves and others. See (Monaghan, 2018) for a recent discussion of police duties to disobey unjust laws.

${ }^{46}$ Thanks to an anonymous reviewer at Episteme for suggesting discussion of epistemic exploitation.
} 
other costs. ${ }^{47}$ In short, to the question of whether marginalized individuals bear moral and epistemic responsibility to educate privileged individuals when given the opportunity, I say this largely depends on the costs associated with providing such education and the confidence providers have that offering such education will be effective. Moreover, it seems there are good reasons to think both of those conditions weigh against moral and epistemic responsibilities attaching to marginalized individuals in many such contexts. Hence, the context-sensitive moral and epistemic principles defended here seem insulated from charges of justifying epistemic exploitation. They also reveal, as should be obvious, the deep complexity of determining responsibility in such contexts.

\subsection{Conclusion}

Having articulated necessary and sufficient conditions for HI, I argued Fricker's proposed remedy HJ - is best understood as constituted by context-sensitive principles that may generate significant epistemic and moral responsibility. Generally, we should listen to and not harm others, but when marginalized individuals are struggling to render experiences intelligible to privileged individuals, the latter have more substantial responsibilities to help. I outlined various caveats concerning these principles, reflecting both the complexity of judgments of moral and epistemic responsibility and contexts in which we might find either. I then argued that though Fricker may balk at accepting these principles and the sometimes substantial responsibility they codify, they provide much needed content to $\mathbf{H J}$, have a clear explanation for the generation of responsibilities on contextual grounds, are defensible independently of $\mathbf{H I}$ and so in that sense may even apply to address background conditions against which the injustice arises, and appear to get the right results when examining complicated scenarios such as responsibilities clinical psychologists bear towards clients as occupants of institutional roles, and when considering whether marginalized individuals have

\footnotetext{
${ }^{47}$ Note, I do not claim the absence of responsibility in these cases stems from the fact that marginalized individuals are not at fault for the conditions they find themselves in. The contextual approach I have taken here finds responsibility independently of personal fault.
} 
responsibilities to educate privileged individuals. I thus conclude Fricker has overwhelming reasons to adopt the explication of $\mathbf{H J}$ offered here.

\section{Works Cited}

Anderson, E. (2012). Epistemic Justice as a Virtue of Social Institutions. Social Epistemology. 26(2): 16373.

Beverley, J. (2016). The Ties that Undermine. Bioethics. 30(5)

Beverley J. \& Beebe, J. (2017). Judgments of Moral Responsibility in Tissue Donation Cases. Bioethics. 32(2).

Beverley, J. \& Reischer, H.N. (2019). Social Support Criterion in Organ Donation. American Journal of Bioethics

Dotson, K. (2011). Tracking Epistemic Violence, Tracking Practices of Silencing. Hypatia: A Journal of Feminist Philosophy. 26(2): 237-57.

Futa, K.T. et. al. (2003). Adult Survivors of Childhood Abuse: An Analysis of Coping Mechanisms used for Stressful Childhood Memories and Current Stressors. Journal of Family Violence. 18(4). 227-39.

Fricker, M. \& Jenkins, K.T. (2017). Epistemic Injustice, Ignorance, and Trans Experience. The Routledge Companion to Feminist Philosophy.

Fricker, M. (2016). Epistemic Injustice and the Preservation of Ignorance. In The Epistemic Dimensions of Ignorance (eds.) Peels, R. \& Blaauw, M. 160-77.

Fricker, M. (2012). An Interview with Miranda Fricker. Social Epistemology. 26(2): 253-63.

Fricker, M. (2009). Can There Be Institutional Virtues? Oxford Readings in Epistemology (Special Theme: Social Epistemology).

Fricker, M. (2007). Epistemic Injustice: Power and the Ethics of Knowing. Oxford and New York: Oxford University Press.

Goetze, T. (2018). Hermenentical Dissent and the Species of Hermeneutical Injustice. Hypatia: A Journal of Feminist Philosophy. 33(1).

Hanel, H. C. (2018). What is Rape? Social Theory and Conceptual Analysis. Bielfeld, Deutschland.

Jenkins, K. (2017). Rape Myths and Domestic Abuse Myths as Hermeneutical Injustices. Journal of Applied Philosophy. 34(2): 191-206.

Kverme B, Natvik E, Veseth M, Moltu C. Moving Toward Connectedness - A Qualitative Study of Recovery Processes for People With Borderline Personality Disorder. Front Psychol. 2019;10:430. Published 2019 Feb 28. doi:10.3389/fpsyg.2019.00430

Kyratsous, M., and Sanati, A. ( 2017) Epistemic injustice and responsibility in borderline personality disorder. J Eval Clin Pract, 23: 974 -980. doi: 10.1111/jep.12609.

Lowe. E.J. (2006). The Four-Category Ontology: A Metaphysical Foundation for Natural Science. Oxford: Clarendon Press.

Mason, R. (2011). Two Kinds of Unknowing. Hypatia: A Journal of Feminist Philosophy. 26(2): 294307.

McAdams, D. P. (2015). The art and science of personality development. Guilford Press.

McMahan, J. (2002). Ethics of Killing: Problems at the Margins of Life. Oxford University Press.

Medina, J. (2017a). Epistemic Injustice and Epistemologies of Ignorance. The Routledge Companion to the Philosophy of Race.

Medina, J. (2017b). Varieties of Hermeneutical Injustice. The Routledge Handbook of Epistemic Injustice.

Medina, J. (2013). The Epistemology of Resistance: Gender and Racial Oppression, Epistemic Injustice, and Resistance Imagination. New York: Oxford University Press. 
Monaghan, J. (2018). On Enforcing Unjust Laws in a Just Society. The Philosophical Quarterly.

68(273):758-778, https://doi.org/10.1093/pq/pqy013

Mills, C. (2007). White Ignorance. In Race and Epistemologies, (ed.) Tuana, S. S. N.

Nguyen, C.I. (2019). Echo Chambers and Epistemic Bubbles. Episteme. 2-21.

Nozick, R. (1969). Coercion. In Philosophy, Science, and Method: Essays in Honor of Ernest Nagel. St. Martin's Press. 440-472.

Polhaus, Jr. G. (2012). Relational Knowing and Epistemic Injustice: Toward a Theory of Willful Hermeneutical Ignorance. Hypatia: A Journal of Feminist Philosophy. 27(4): 715-35.

Tremain, S. (2016). Knowing Disability, Differently. The Routledge Handbook on Epistemic Injustice.

Reischer, H. N., \& Cowan, H. R. (2020). Quantity Over Quality? Reproducible Psychological Science from a Mixed Methods Perspective. Collabra: Psychology, 6(1), 26.

DOI: http://doi.org/10.1525/collabra.284

Romdenh-Romluc, K. (2016). Hermeneutical Injustice: Blood-Sports and the English Defense League. Social Epistemology.

Simion, M. (2018). Hermeneutical Injustice as Basing Failure. In Well-Founded Belief: New Essays on the Epistemic Basing Relation. (eds.) Carter, J.A. \& Bondy, P.

Smith, B. \& Spear, A. \& Ceusters, W. (2016). Functions in Basic Formal Ontology. Applied Ontology. 11. 103-128.

Sullivan, Patrick. "Epistemic Injustice and Self-Injury: A Concept with Clinical Implications." Philosophy, Psychiatry, \& Psychology, vol. 26 no. 4, 2019, p. 349-362. Project MUSE, doi:10.1353/ppp.2019.0049.

Van Loon, et. al. (2005). Reclaiming Myself after Child Sexual Abuse. Glenside, St. Augustine Research Unit.

Ward, C. (1988). Stress, Coping, and Adjustment in Victims of Sexual Assault: The Role of Psychological Defense Mechanisms. Couns. Psych. Q. 1:165-78.

Williams, N.E.W. (2019). The Powers Metaphysic. Oxford University Press. 